\title{
The Effects of Diagnosis on Learning Engineering Graphics and Design in a First Year University Degree Course in South Africa
}

\author{
Samuel Dumazi Khoza \\ University of the Witwatersrand
}

\begin{abstract}
Engineering Graphics and Design (EGD) is a technological subject that the students of South African universities take when they enroll for their four-year degree course in Technology Education. Most students enter into the programme without having studied EGD at secondary school level. As soon as they take EGD in their first year of study they become reluctant to continue with it up to their degree completion. This study therefore seeks to show the effects of diagnosis towards learning EGD in a first year degree course in South Africa. The study made use of a qualitative approach where focus group interviews were conducted with 65 first year degree students learning EGD. A total of three universities offering EGD in South Africa took part in the study. Findings revealed that after students were taken through a bridging programme, students realized that line-work was very useful in EGD and the bridging programme provided them with the necessary skills to visualize drawings when drawing. Lecturers also had a better plan to prepare students for the academic year and the students' performance in EGD concepts was better than in previous years.
\end{abstract}

\section{Introduction and background}

In the engineering world, Engineering Graphics and Design (EGD) is the medium of communication through drawings. It relates to theory and the picture of reality, the same way as Technical drawing does. EGD provides an accurate and complete picture for every object in terms of shape and size in the technology related fields [12]. On the other hand, Benade and Van Der Heever define EGD as a graphic language that enables technicians and engineers to describe the exact size and shape of physical objects [1].

EGD is a compulsory technology subject for most of the students enrolling in a Bachelor's Degree in Technology Education programme in South African universities. Most of these students come into the programme without any idea as to the nature of EGD. The admission criteria into the Bachelor Degree in Technology Education programme in most universities in South Africa is flexible such that anyone with Mathematics, Physical Science and/or Technical subjects in Grade 12 is qualified to enroll into the programme.

As soon as students realize that EGD is more technical and abstract in nature (during their first year of study, and without having studied it at secondary school level) they become reluctant to continue with EGD throughout their degree programme and drop it for other common subjects like Physical Science, Mathematics, Information Technology and so forth. This reduces the output rate of students with EGD when they graduate because students will have opted for other subjects in their Bachelor's degree programme. The graduation rate of students with EGD in most universities in South Africa used to be very low because of this problem. This study was therefore conducted in three universities in South Africa which offer a Bachelor Degree in Technology Education and which have experienced a low enrolment rate and low graduation rate of students with EGD.

According to the study that was conducted by Khoza and Makgato on the degree students in another university based in the Eastern Cape in South Africa, it was found that students who learn EGD need spatial visualization skills to understand its concepts [6]. Sorby suggests that those who enroll in the EGD course need to have attended some courses related to spatial visualization skills [9]. Meanwhile, spatial visualization ability has been recognized as a predictor of success in many technology related fields, EGD included [10]. Khoza and Makgato found that most of the EGD students committed the following errors during drawing [6]:

- Incorrect application of line-work.

- They did not have visualization skill (which is a predictor of the successful learning of EGD and all its concepts).

- They were also slow in completing a given 
drawing task in the classroom.

The above errors that EGD students committed led to the researchers Khoza and Makgato coming up with an intervention that was employed first at a university based in the Eastern Cape before the intervention was tested in other South African universities [6]. In the meantime, EGD emphasis is focused on the correct use of tools and equipment, drafting media, sketching, lettering, alphabet of lines, geometric construction, fundamentals of Computer Aided Draughting (CAD) and multiview drawings [13]. On the other hand lecturers who facilitate EGD in some of the universities in South Africa have challenges in the successful facilitation of EGD. They gave varied reasons for challenges that they come across in facilitating EGD to first year degree students. Some of these reasons were:

- Students take EGD because they are forced to do it since it is a compulsory subject in their Education Technology course.

- Students lack EGD background from secondary school.

- $\quad$ Students do not buy drawing instruments.

- Students practice EGD only when they are given a task or about to write a test.

- Students commit basic mistakes like using wrong line-types in a sketch etc.

The above lecturers' challenges showed that facilitating EGD to the first year degree students in a university is not an easy task. The fact that most first year students come into the programme without an EGD background will definitely create challenges in students' learning of EGD and its concepts. According to Brink et al. technical drawing demands the basic knowledge and skills of EGD at Grade 9 level of the NCS curriculum, where graphic communication is studied [2]. Therefore if a student lacks the basics of EGD concepts like line-work, sketching, and drawing interpretation, they are most likely to struggle with doing EGD successfully. Line-work assists students to visualize a drawing and be able to identify hidden features of a drawing [2].

\section{The development of the EGD learning intervention}

The intervention in teaching and learning EGD was a bridging programme which was employed with the new university students studying Technology Education with EGD as one of their major subjects. This bridging programme resulted from a study that was undertaken in a university based in the Eastern Cape, South Africa, with the Technology Education students after a diagnosis exercise before the start of the academic year [5]. The bridging course introduced basic EGD skill exercises in order to prepare new students who entered the degree programme without an EGD background and it ran for four weeks before the commencement of the academic year.

The students, who had been doing EGD since secondary level, especially from Grade 10 with $60 \%$ or a Level 4 pass in Grade 12, were given the option of deciding whether or not to be part of the bridging programme. The reason these students were given the choice was because the bridging programme consisted more of EGD basics that are covered in Grade 8 to Grade 10, which prepare students to do complex concepts of EGD from Grade 11 and beyond. The programme tests for basic skills that students need to enhance their spatial skills ranging from line-work and sketching to visualization (see Table 1 below):

Table 1: Four weeks EGD bridging programme

\begin{tabular}{|l|l|l|l|}
\hline No. & Topic & $\begin{array}{l}\text { Weight } \\
\text { values }\end{array}$ & Week ending \\
\hline 1. & Introduction to Fundamentals of Sketching & $10 \%$ & 1 \\
\hline 2. & Visualization and Spatial Representation & $25 \%$ & 2 \\
\hline
\end{tabular}




\begin{tabular}{|l|l|l|l|}
\hline 3. & $\begin{array}{l}\text { Drawing Projections: Orthographic, Isometric, Sectional, } \\
\text { Auxiliary Views }\end{array}$ & $30 \%$ & 3 \\
\hline 4. & Dimensioning, Geometric Dimensioning \& Tolerance & $10 \%$ & 3 \\
\hline 5. & Working Drawing Requirements & $10 \%$ & 4 \\
\hline 6. & Design Project & $15 \%$ & 4 \\
\hline \multicolumn{2}{c|}{ Total } & \multicolumn{2}{|c|}{$\mathbf{1 0 0 \%}$} \\
\hline
\end{tabular}

Source: [5] Adapted from [9]

The table above shows how the bridging programme allows new university degree students to learn basic EGD skills and how to draw straight lines as stipulated in the EGD curriculum - this skill should last for a week. In the second week simple figures are then given for them to determine the obscured or missing view. During the third week students are given a three-dimensional (3D) drawing so that they can produce three views as seen from three different sides. This skill is called first or third Angle Orthographic Projection (FAOP) or (TAOP). First Angle Orthographic projection is a multi view of an object placed in the first quadrant, whereas an object is placed in the third quadrant in Third Angle Orthographic projection [11]. An example of FAOP and TAOP questions are given below: 
Figure 1: Typical Orthographic Projections
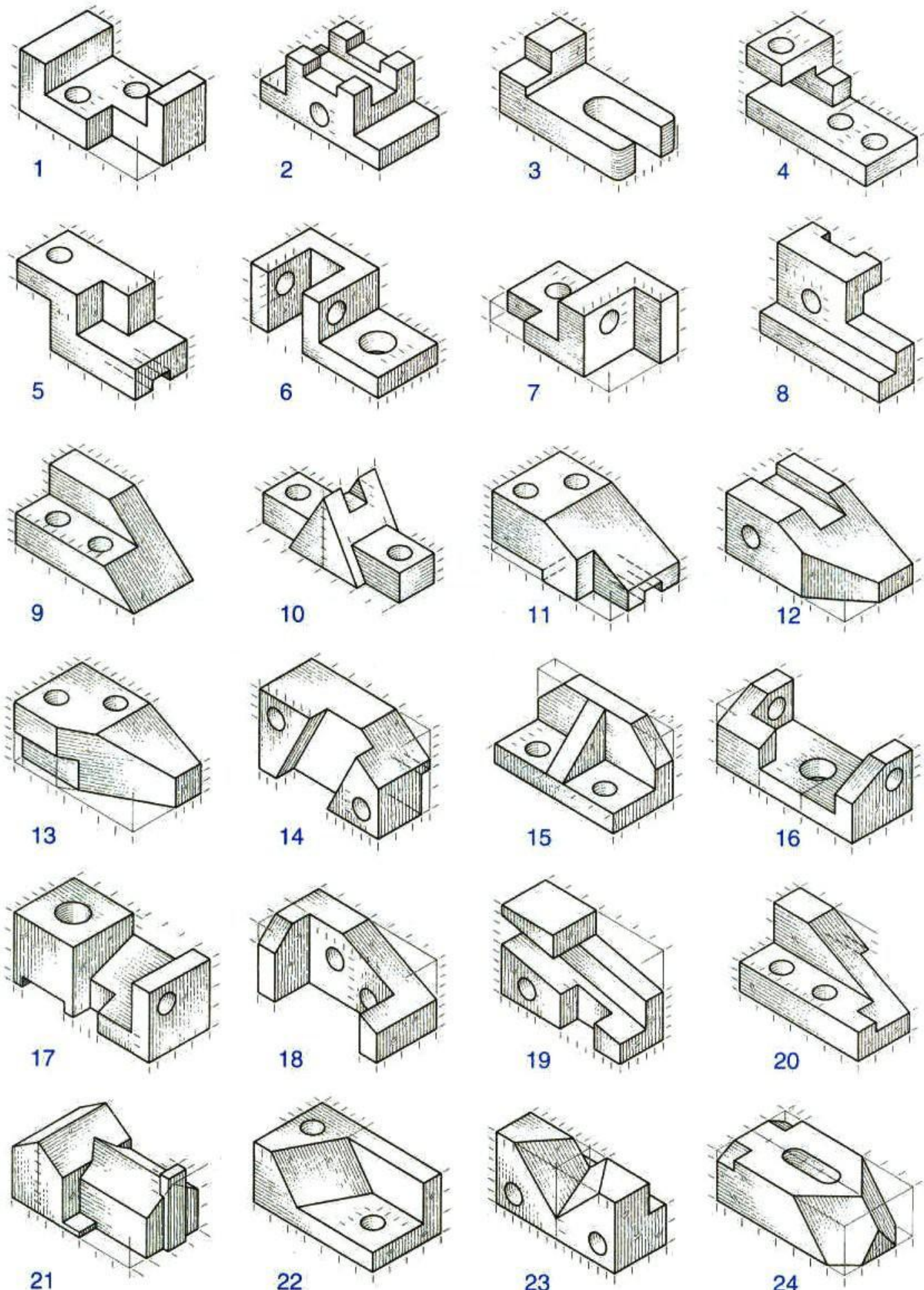

Source: [14]

The above figure is a typical example of FAOP and TAOP drawings of the bridging programme where students will be taught to draw three views of each drawing in both FAOP and TAOP. The aim of the exercise is to assist students by showing them the difference 
between FAOP and TAOP. The difference is that the front view of a FAOP drawing is when a $3 \mathrm{D}$ drawing is viewed from the right hand side whereas the front view of a TAOP drawing is seen when a $3 \mathrm{D}$ drawing is looked at from the left hand side [7]. Also this helps

Figure 2: A typical FAOP question and a solution

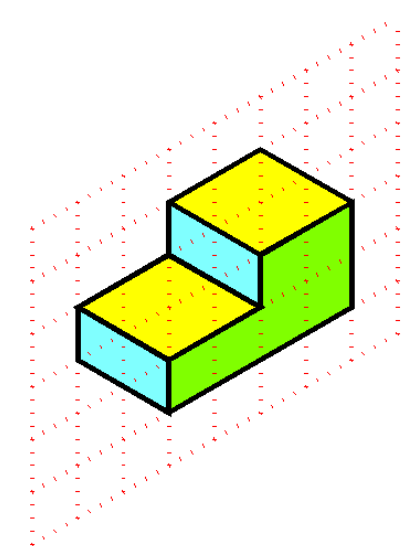

Pictorial view 1

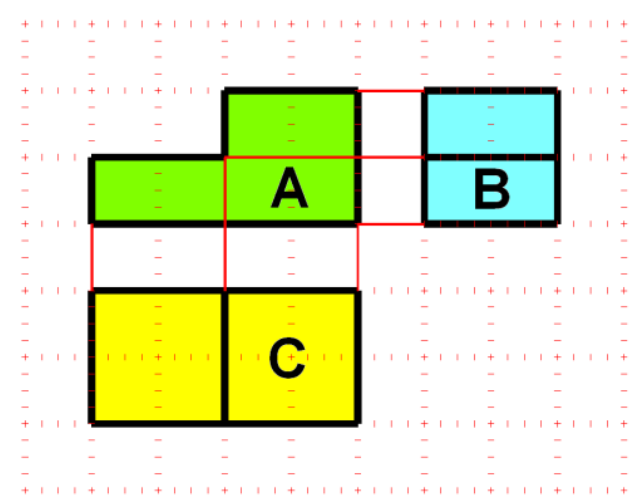

Solution

Source: [5]

The above figure shows a 3D drawing which was used to assist students to draw three views as seen from the three sides in FAOP. The solution shows drawings $\mathrm{A}, \mathrm{B}$ and $\mathrm{C}$. Drawing $\mathrm{A}$ is the front view of pictorial view 1 as seen from the right hand side. This was one of the skills that students had to learn in their third week of the bridging course, which required students to apply the skill that they Figure 3: A typical TAOP question and a solution the students in clarifying the technique of the production of the three views of each drawing - that in FAOP we do have a left view whereas in TAOP there is not a left view but a right view. A typical example of the two projections is shown in the figures below: 

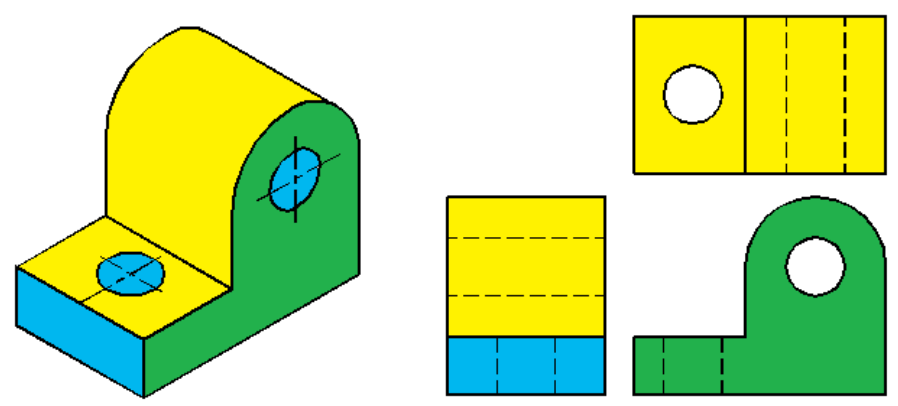

Pictorial view 2 and a solution

Source: [5]

Figure 3 above shows a TAOP question, which tested the same skill as in Figure 2. The difference in the acquired skill is that the front view in a TAOP drawing is seen from the left hand side as shown on the solution of Figure 3 and the bottom right drawing of the same solution of Figure 3 is the right view. These skills assist students to improve their visualization skill in order to cope with other complex EGD concepts along the degree curriculum. These skills are reflected in almost $80 \%$ of the South African universities' EGD curricula and a failure to understand the basics of these skills will cause students to struggle to apply these skills in other complex EGD concepts.

\section{Errors that students commit in Orthographic projection questions}

Students in a first year degree course often commit basic errors when producing an orthographic projection drawing. The figures below show examples of simple drawings that students can be asked in order to provide three views as seen from three various sides. The phrasing of the question would be: "Study the given drawings below and draw in First Angle Orthographic Projection, the Front view, the left view and a top view." 
Figure 4: 3D models of a BLOCK

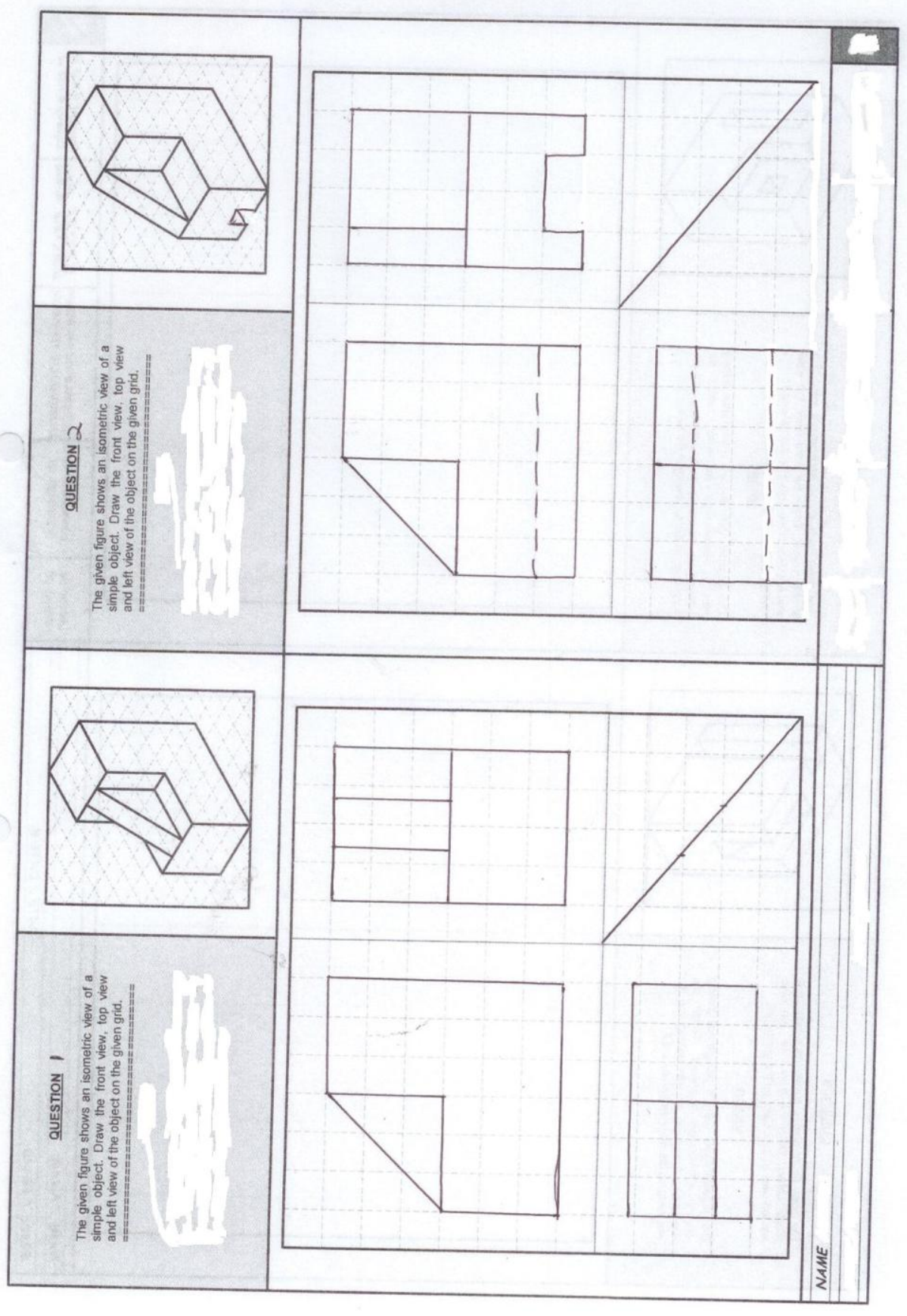

Source: [3]

The above sketches are represented in a 3D format and the students are required to draw in FAOP (1) Front views, (2) Left views and (3) Top views in the spaces below each sketch. The sketches are provided with a space for a solution under each 3D drawing. However students, especially those who have no EGD background from school level, respond by representing the drawings with basic mistakes ranging from incorrect use of line-work, wrong positioning of sketches and sketches with missing features like holes, grooves etc. An 
example of a student's solution on Figure 4 above shows some of the basic mistakes that were alluded to above.

\section{Figure 5: Student's solution}

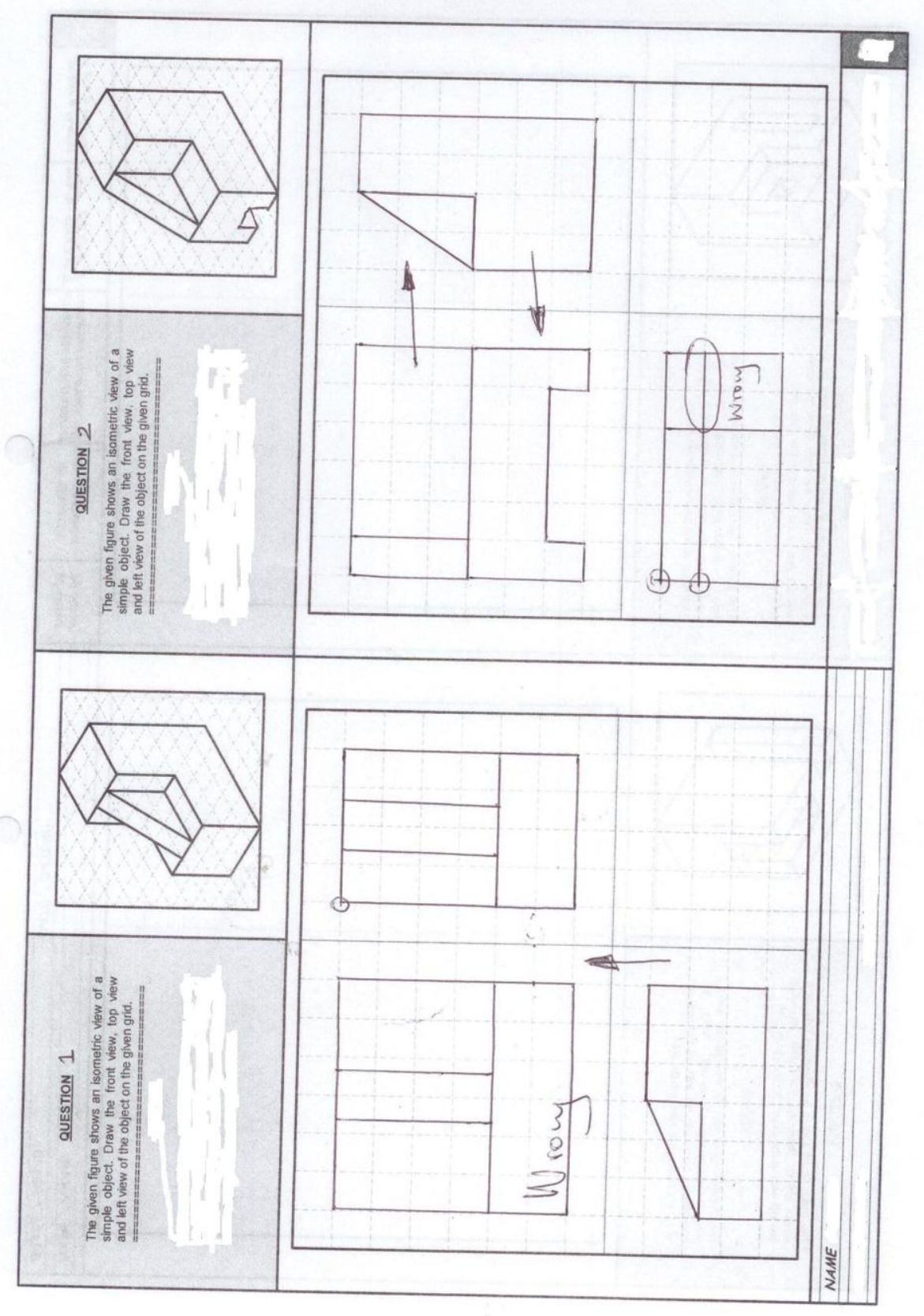

Source: [3]

The above figure is a solution to Figure 4 above of a BLOCK showing the basic mistakes that students normally commit. The omission of hidden details or dashed lines in the 
student's solution changes the true image of the sketch because hidden details serve a purpose of assisting the students/draughtsman/engineers in identifying underlying components in a drawing when designing technical projects [7]. Similar errors repeat themselves quite often and when EGD comes to an advanced stage in the students' degree course, students do not cope with concepts like assembly and detail drawings that carry a lot of marks. They even become reluctant to teach EGD or some of its concepts when they go out to their teaching practice. The other error that students commit is the rearrangement of views; arrows that are shown on the student's solution show where exactly the view was supposed to be projected. Therefore the introduction of the bridging programme assisted the researcher in providing first year degree university students with skills in order to learn EGD with ease in complex concepts of their curriculum.

\section{Research questions}

The completion of the bridging programme was succeeded by the following research questions that were directed to students in the focus group interviews:

RQ1: What are the critical elements towards learning Engineering Graphics and Design?

RQ2: How can challenges towards learning Engineering Graphics and Design be avoided?

\section{Methodology}

The study made use of a qualitative approach where students were taken through a bridging programme that was established through the findings of the researcher's previous study. Qualitative research usually has no measurements or statistics but uses words, descriptions and quotes to explore meaning. It can even use arts techniques, such as dance [8]. Three universities in three different provinces in South Africa became part of the study. These universities had challenges ranging from students not taking EGD in large numbers until the final fourth year of the course, students failing to graduate on time due to the fact that they had failed EGD during their studies, to students who were reluctant to teach EGD during their teaching practice because they lacked confidence in themselves.

A total of 65 first year university students (20 each from two universities and 25 from the third university) became part of the bridging programme that ran for four weeks with the fifth week used to assess students on basic EGD skills. Focus group interviews were conducted with the 65 students after they went through the bridging programme. According to a study carried out at the University of Florida, Institute of Food and Agricultural Sciences (IFAS) Extension, a focus group is a planned, relaxed, naturalistic dialogue among a small group of people on a specific topic [4]. The advantage of focus groups over one-on-one interviews is that information can be obtained more quickly because only one interview must be scheduled for a group, rather than one for each person.

Universities A and B each had 20 students who were grouped into four groups with five members in each group. The students at university $C$ were in five groups each consisting of five students. Lecturers at each university that took part in the study were provided with a tailor-made course in order to facilitate the first year university students for the first four weeks before the commencement of the academic year. During the fifth year the researcher then assessed the students. The researcher then shared the students' marks with their respective lecturers so that proper planning of the academic year could be done in accordance with students' performance. Judgmental sampling was used to select these first year EGD students based on their Grade 12 results. Therefore there was no pre-test for the first year EGD students because the criteria for the students' selection were based on their lack of EGD Grade 12 background. Results obtained after assessing students on the bridging programme laid a clear foundation for the approach that ought to be taken during the students' academic year.

\section{Results and discussion}

The focus group interviews with first year degree university students produced the following two themes:

- Correct use of line-work and visualization as important skills towards learning EGD.

- Possession of drawing instruments as a driving factor to producing good sketches.

The above two themes were obtained from the focus group interviews with first year degree students. A student from university A (Lucas) said the following: "I now know that line-work is the basis of drawing and I now 
know why these lines are so important in EGD." Another student (Tshepo) from the same university noted: "I am often told that line-work offers the difference between features in EGD and I now can differentiate these lines."

On the other hand, a student from university B (Sam) said the following: "I do know the importance of various line-types because they help me in differentiating the features in the object." His fellow classmate (Linda) said: "If a teacher knows the importance of various line-types they will know the description of the drawing in both size and shape and be in a better position to explain to his/her learners in class, therefore line-work is critical in EGD."

In the meantime a student at university $\mathrm{C}$ said the following: "Ever since the past few weeks of this programme I am able to produce a missing view and projecting it with instruments and in freehand through these basic skills that I have learnt." This supports what Brink et al. said earlier in this study that technical drawing demands the basic knowledge and skills of EGD [2].

The responses above show that students realized that line-types are important. As discussed by Moolman and Brink earlier in this study, line-work enables students to communicate ideas graphically in their Engineering career because students see the importance of line-work in EGD during the bridging programme [7]. This translates into line-work being the key factor in students' understanding of any drawing concept as a foundation for drawing activities. This confirms what Widad and Adnan said earlier in this study that good drawings enable a student to do sketching and line-work efficiently and effectively [12].

These responses also cement what Benade and Van Der Heever say that EGD is a graphic language that enables technicians and engineers to describe the exact size and shape of physical objects and that visualization becomes enhanced as alluded to earlier by Khoza and Makgato, Strong and Smith as well as Sorby [1] [6] [9] [10].

\section{Conclusion}

The study reveals that students are keen to take EGD into their Bachelor Degree programme despite their poor EGD background. Most of the students appreciated the bridging programme and realized that good line-work serves as a key indicator towards the successful learning of EGD and all its concepts. The fact that students come into the programme and end up with the ability to produce a missing view from the given exercises, shows that the bridging programme enhances students' spatial skills. Their learning of line-work in their bridging programme also enables students to identify key features of an object during drawing.

Therefore the study as well as students' responses shows that diagnosis serves as a key indicator towards learning EGD because learning barriers are identified timeously. The bridging programme made it clear and easy for the lecturers to plan for that academic year. When approached for their personal comments, lecturers in the universities where the study was conducted said that students' performance thus far in EGD concepts had improved as compared to previous years and that some of their students were even demanding difficult tasks.

\section{References}

[1] Benade, D.C. \& Van Der Heever, Z.J. (1994). Modern Technical Drawing Grade 12. Zachen Publishers. Pretoria.

[2] Brink, C.G., Gibbons, P.J. \& Theron, A.E. (1997). Engineering Drawing N1. Johannesburg: Heinemann.

[3] Engelbrecht, J. (2000). Technical Drawing Workbook Grade 8. HSE cc.: Pretoria.

[4] Israel, D.G. \& Galindo-Gonzalez, S. (2008). Using Focus Group Interviews for Planning or Evaluating Extension Programs. University of Florida. IFAS Extension.

[5] Khoza, S.D. (2013). Diagnosis as a Key Performance Indicator to Learning Engineering Graphics and Design: A case of Technology Education students in a university based in the Eastern Cape Province. Ireland International Conference on Education Proceedings, 2014. Dublin, Ireland.

[6] Khoza, S.D. \& Makgato, M. (2013). Students' difficulties in sectional drawing: A case of student teachers in the Eastern Cape University. SAARMSTE Conference. Western Cape. South Africa.

[7] Moolman, C.L. \& Brink, C.G. (2010). Engineering Drawing N3. ( $3^{\text {rd }}$ ed.). Heinemann. Johannesburg.

[8] Picard, C. (2000). Pattern of expanding consciousness in midlife women: creative movement and the narrative as modes of expression. Nursing Science Quarterly. 13(2), 150-157. 
[9] Sorby, S.A. (2003). Introduction to 3D Spatial Visualization: An Active Approach. Clifton Park, N.Y.: Thomson/Delmar Learning.

[10] Strong, S. \& Smith, R. (2002). Spatial visualization: Fundamentals and trends in engineering graphics. (Digital ed.), J. of Industrial Technol. 18(1), 1-5.

[11] Theron, A. \& Moodley, D. (2008). Engineering Graphics and Design: Learners' Book Grade 12. Guidelines: An Imprint of Macmillan South Africa (Pty) Ltd. Cape Town.

[12] Widad, O. \& Adnan, A. (2000). Teachers' Thinking Style In Solving Engineering Drawing Problems. Proceedings of International Conference On Technical \& Vocational Education. 21-23 November 2000. Petaling Jaya: Institute.

[13] Widad, O., Rio, S.S. \& Lee, M.F. (2006). Eengineering drawing (eed ${ }^{\mathrm{TM}}$ ) - a web based system for teaching and learning engineering drawing for upper secondary schools. The $6^{\text {th }}$ SEAAIR annual conference; Langkawi, September 5-7.

[14] http://www.gr8lessons.com/files.ortholso.pdf (2010) 